\title{
Diabetic Retinopathy and Homocysteine in Newly Diagnosed Type 2 Diabetes Mellitus
}

\author{
Md. Rezwanur Rahman1, M Iqbal Arslan², Md. Mozammel Hoque³, Md. Waliur Rahman4, Shahana Shermin 5
}

\begin{abstract}
Background: Diabetic retinopathy is the commonest complication that occurs from the very beginning in patients with diabetes mellitus (DM). DM itself leads to increased homocysteine (Hcy) level. It is postulated that hyperhomocysteinaemia causes retinal vascular damage as Hcy is an established vasculotoxic agent and auto-oxidation of Hcy leads to oxidative stress, endothelial dysfunction, platelet activation and thrombus formation. Objective: The aim of the study was to evaluate the serum Hcy in newly diagnosed type 2 diabetic subjects with diabetic retinopathy. Materials and method: A case control study was carried out in the department of Biochemistry, Bangabandhu Sheikh Mujib Medical University, Dhaka, during the period of January 2006 to December 2007. Total 85 newly diagnosed type 2 diabetic subjects were included in this study, 40 were case having retinopathy and 45 were age and sex matched control without retinopathy. Serum Hcy was measured and compared between case and control. Results: Serum Hcy level in cases was significantly higher $(p<0.05)$ compared to that of control $(15.11 \pm 5.49 \mu \mathrm{mol} / \mathrm{L}$ vs. $12.59 \pm 4.01 \mu \mathrm{mol} / \mathrm{L})$. Odds ratio was also determined for hyperhomocysteinemia $(O R=2.23$; CI 0.9-5.45). Conclusion: Hyperhomocysteinaemia is associated with diabetic retinopathy in newly diagnosed type 2 diabetes.
\end{abstract}

Keywords: Homocysteine (Hcy); hyperhomocysteinaemia; diabetic retinopathy.

Delta Med Col J.Jul 2013;1(2):37-41

1. Associate Professor, Dept. of Biochemistry, Delta Medical College, Dhaka, Bangladesh.

2. Professor, Dept. of Biochemistry, Bangabandhu Sheikh Mujib Medical University, Dhaka, Bangladesh.

3. Professor, Dept. of Biochemistry, Bangabandhu Sheikh Mujib Medical University, Dhaka, Bangladesh.

4. Medical officer, Dept. of Biochemistry, Bangabandhu Sheikh Mujib Medical University, Dhaka, Bangladesh.

5. Senior Medical officer, Dept. of Obs \& Gyn, BIRDEM, Dhaka, Bangladesh.

Correspondence: Dr. Md. Rezwanur Rahman. e-mail:rezwanrahman5@yahoo.com

\section{Introduction}

Diabetic retinopathy is a well characterized, sight threatening, chronic, ocular disorder that eventually develops to some degree in nearly all patients with diabetes mellitus (DM). The pathologic changes associated with diabetic retinopathy are similar in type 1 and type 2 diabetes mellitus, although there is a higher risk of more frequent and severe ocular complications in type 1 diabetes. However, because more patients have type 2 than type 1 disease, patients with type 2 disease account for a higher proportion of those with visual loss. ${ }^{1}$
Among the microvascular complications of diabetes, retinopathy is the most common one. Diabetic retinopathy is the most frequent cause of new cases of blindness among adults aged 20-74 years and it results in blindness for over 10,000 people with diabetes per year in the United States. At the time of diagnosis of type 2 diabetes, about $21 \%$ patients have established retinopathy and twenty years after the onset of diabetes over $60 \%$ of patients with type 2 diabetes will have some degree of retinopathy. 2 
Chronic hyperglycaemia is considered to be the major risk factor for diabetic retinopathy, by inducing several biochemical pathways resulting in increased oxidative stress leading to endothelial dysfunction in the retinal precapillary arterioles, capillaries, and venules. These result in both microvascular leakage from breakdown of the inner blood-retinal barrier and microvascular occlusion leading to diabetic retinopathy.3-5

Although diabetic patients with the most severe hyperglycaemia have the highest risk of diabetic retinopathy, hyperglycaemia, however, is a necessary, but not a sufficient cause of this. Among the other well known contributing factors, hyperhomocysteinaemia is also associated with the development and progression of retinopathy. 4,6

Homocysteine (Hcy) is a highly reactive thiol-containing amino acid derived from the conversion of methionine to cysteine, producing reactive oxygen species - hydrogen peroxide and superoxide anion radical.7,8 Elevated plasma Hcy is vasculotoxic as it causes endothelial dysfunction, increased oxidative stress, altered coagulation / fibrinolysis, smooth muscle cell proliferation, and changes in structural and elastic properties of the vessel wall. It also limits nitric oxide (NO) production and promotes lipid peroxidation thereby decreasing the bioavailability of NO. In diabetes the pro-oxidative state worsens by auto-oxidation of Hcy leading to additional oxidative stress and thereby to endothelial dysfunction, platelet activation and thrombus formation.9-11

Insulin resistance, which is the fundamental abnormality in the pathogenesis of type 2 diabetes, may lead to arterial damage through toxic effects of hyperinsulinaemia. Finding of no association between insulin resistance and hyperinsulinaemia with atherogenesis in some but not all studies, suggests that previously unmeasured factors may be involved in the link between hyperinsulinaemia, endothelial dysfunction and atherosclerosis. One potential factor may be variation in plasma levels of Hcy, because elevated levels of Hcy are toxic to vascular endothelium, inducing endothelial dysfunction and contributing to development of atherosclerosis independent of standard atherogenic risk factors in diabetic and nondiabetic subjects. 12
Hyperinsulinaemia may result in an increase of plasma Hcy level but the mechanisms regulating Hcy metabolism in human remain largely undefined. Increased plasma level of insulin seems to influence Hcy metabolism through effects on glomerular filtration or by influencing activity of methyltetrahydrofolate reductase (MTHFR) and hepatic cystathione $\beta$ synthase (CBS). Insulin has been demonstrated to down-regulate the activity of hepatic enzymes of Hcy transsulfuration-oxidation. Several studies have suggested that moderate hyperinsulinaemia could raise plasma Hcy level in patients with insulin resistance by reducing Hcy transsulfuration. ${ }^{13,14}$

McCarty reported that hyperinsulinaemia suppresses hepatocyte expression of cystathione beta-synthase in animal models. He also suggested that other measures which enhance diurnal insulin secretion, such as a high-glycaemic-index diet, can be expected to increase homocysteine levels. ${ }^{15}$

Another factor contributing to hyperhomocysteinaemia in type 2 diabetes may be related to the effect of insulin on protein and amino acid metabolism. It is well recognized that insulin decreases plasma methionine, the methionine being incorporated into newly synthesized protein. Plasma amino acid concentrations, including methionine, fall significantly after a rise in endogenous plasma insulin following an oral glucose load. However, in patients with diabetes, this fall in amino acids does not occur, indicating a possible resistance to insulin's effect on amino acids in diabetics. Such a resistance to insulin's effect on methionine may contribute to the hyperhomocysteinaemia associated with insulin resistance syndrome and type 2 diabetes. ${ }^{16}$

As a good percentage of type 2 diabetic patients present with retinopathy with or without other microvascular complications at diagnosis, measurement of Hcy may open a new window for determining the additive risk factor in the development of retinopathy in type 2 diabetic patients from the very beginning. In our country till no study has been conducted addressing Hcy in diabetes mellitus with or without retinopathy. So our aim was to evaluate the role of Hcy in retinopathy in type 2 diabetes mellitus. 


\section{Materials and method}

This case control study was conducted in the department of Biochemistry, Bangabandhu Sheikh Mujib Medical University, Dhaka during the period of January, 2006 to December, 2007. A total of 85 newly diagnosed type 2 diabetic patients were enrolled purposively with predefined inclusion and exclusion criteria. Among them 40 were cases having diabetic retinopathy and rest 45 were age and sex matched controls without any sort of diabetic complication. Serum Hcy was determined by fluorescence polarization immuno assay (FPIA). ${ }^{17}$ Fundoscopy was performed by expertise.18,19 Data were recorded systematically in a preformed data collection sheet and were analyzed by SPSS 12.0 for Windows. Mann-Whitney $U$ test was done to find significant difference between groups. Unpaired $t$ and Chi-square test were done as the test of significance for age and sex respectively. Odds ratio $(95 \% \mathrm{CI})$ was calculated to determine the association of Hcy with diabetic retinopathy in study subjects.

\section{Results}

Age range of cases was 29 to 65 years with mean age of $44.65 \pm 8.80$ years. Where in controls the age range was 30 to 65 years with mean age of $44.04 \pm 9.09$ years. Among the cases 17 were male and 23 were female and among the controls 20 were male and 25 were female. No significant difference $(p>0.05)$ was observed regarding age and sex distribution between case and control (Table I).

Table I: Distribution and comparison of age between case and control $(\mathrm{N}=\mathbf{8 5})$

\begin{tabular}{|c|c|c|c|c|c|}
\hline \multirow{2}{*}{$\begin{array}{l}\text { Study } \\
\text { subjects }\end{array}$} & \multirow[b]{2}{*}{ Mean age (yrs) } & \multirow[b]{2}{*}{$\mathbf{t} / \mathbf{p}$} & \multicolumn{2}{|c|}{ Sex } & \multirow[b]{2}{*}{ Chi-square / p } \\
\hline & & & Male & Female & \\
\hline \multirow{4}{*}{$\begin{array}{l}\text { Case } \\
(n=40)\end{array}$} & $44.65 \pm 8.80$ & & 17 & 23 & \\
\hline & $(29-65)$ & & & & \\
\hline & & $0.756 /$ & & & $0.033 /$ \\
\hline & & $>0.05$ & & & $>0.05$ \\
\hline Control & $44.04 \pm 9.09$ & & 20 & 25 & \\
\hline$(n=45)$ & $(30-65)$ & & & & \\
\hline
\end{tabular}

Parenthesis shows range
Table II shows the serum concentration of Hcy in cases and controls, expressed in mean $\pm \mathrm{SD}$ and with median value. Mean \pm SD of serum Hcy concentration of cases and controls were $15.11 \pm 5.49 \mu \mathrm{mol} / \mathrm{L}$ (range 7.27 to $30.68 \mu \mathrm{mol} / \mathrm{L}$ ) and $12.59 \pm 4.01 \mu \mathrm{mol} / \mathrm{L}$ (range 6.63 to $25.58 \mu \mathrm{mol} / \mathrm{L})$ respectively. The median value was $14.34 \mu \mathrm{mol} / \mathrm{L}$ and $11.37 \mu \mathrm{mol} / \mathrm{L}$ in cases and controls respectively. Due to non parametric distribution of Hcy, Mann-Whitney U test was done which showed significantly higher $(\mathrm{p}<0.05)$ serum Hcy level in cases in comparison to controls.

Table II: Distribution of serum Hcy in the study subjects $(\mathbf{N}=\mathbf{8 5})$

\begin{tabular}{lcccc}
\hline Study subjects & $\begin{array}{c}\text { Mean } \pm \text { SD } \\
(\mu \mathrm{mol} / \mathrm{L})\end{array}$ & $\begin{array}{c}\text { Median } \\
(\boldsymbol{\mu m o l} / \mathrm{L})\end{array}$ & $\begin{array}{c}\text { Mann-Whitney } \\
\mathbf{U} \text { value }\end{array}$ & $\mathbf{p}$ - value \\
\hline $\begin{array}{l}\text { Case } \\
(\mathrm{n}=40)\end{array}$ & $\begin{array}{c}15.11 \pm 5.49 \\
(7.27-30.68)\end{array}$ & 14.34 & & \\
$\begin{array}{l}\text { Control } \\
(\mathrm{n}=45)\end{array}$ & $\begin{array}{l}12.59 \pm 4.01 \\
(6.63-25.58)\end{array}$ & 11.37 & 665.00 & $<0.05$ \\
\hline
\end{tabular}

Parenthesis shows range

Taking Hcy level of $15 \mu \mathrm{mol} / \mathrm{L}$ as the cut off value, risk for the occurrence of disease was assessed in study subjects which revealed hyperhomocysteinemia as a risk factor for diabetic retinopathy $(\mathrm{OR}=2.23)$ (Table III).

Table III: Risk assessment of diabetic retinopathy by odds ratio in hyperhomocysteinaemia of total study subjects $(\mathrm{N}=85)$

\begin{tabular}{ccccc}
\hline Hcy $(\boldsymbol{\mu m o l} / \mathrm{l})$ & $\begin{array}{c}\text { Diabetic } \\
\text { retinopathy }\end{array}$ & $\begin{array}{c}\text { Without diabetic } \\
\text { retinopathy }\end{array}$ & Total & OR (95\%CI) \\
\hline$>15$ & $19(59.38 \%)$ & $13(40.62 \%)$ & 32 & \\
$<15$ & $21(39.62 \%)$ & $32(60.38 \%)$ & 53 & $(0.9-5.45)$ \\
Total & 40 & 45 & 85 & \\
\hline
\end{tabular}

\section{Discussion}

In this case control study our attempt was to evaluate the role of Hcy in development of diabetic retinopathy in newly diagnosed type 2 diabetes mellitus. We have compared serum Hcy concentration between 40 newly diagnosed type 2 diabetes mellitus cases with retinopathy and age and sex matched 45 controls of newly diagnosed type 2 diabetes mellitus without retinopathy. 
Serum Hcy concentration in cases was found to be significantly higher than that of controls and this finding is similar to that of several other studies done previously. ${ }^{20-24}$ But Tarkun et al. ${ }^{13}$ and Agulló-Ortuño et al. 25 could not find any significant difference in Hcy level between subjects with and without diabetic retinopathy which might be due to their relatively small sample size.

Our study also revealed that hyperhomocysteinaemia might be a risk factor for diabetic retinopathy in newly diagnosed type 2 diabetes mellitus [odds ratio of 2.23 $(\mathrm{CI}=0.9-5.45)]$ which is in line with findings of Brazionis et al. Hoogeveen et al. and Becker et al. $24,26,27$

Apart from the fixed and modifiable traditional risk factors in relation with diabetic retinopathy some newly emerging modifiable risk factors has been addressed in the field of biomedical research and hyperhomocysteinaemia is one of them which is also supported by our study. Though our study may have limited application to be generalized because of relatively small sample size and lack of controlling some confounders, still it can be strongly suggested that Hcy evaluation may serve to identify diabetic patients predisposed to sight threatening complication who may benefit from intensified screening and treatment strategy, including vitamin B6, B12 and folic acid supplementation at diagnosis from where we can try to revert, limit or prevent the incidence and progression of diabetic retinopathy.

\section{References}

1. Aiello LP. Eye complications of diabetes. In: Kahn CR, editor. Atlas of diabetes. Cleveland Street, London: Science Press Limited; 2000.p.136.

2. Fong DS, Aiello LP, Ferris FL, Klein R. Diabetic retinopathy. Diabetes Care. 2004;27(10):2540-53.

3. Watkins PJ. ABC of diabetes: Retinopathy. BMJ. 2003;326:924-26.
4. van Hecke MV. Diabetic Retinopathy. In relation to risk factors, cardiovascular disease and mortality [Internet] 2005. [cited 2007 March 16]. Available from: http://www.researchschoolcare.nl/content/view/142/153.

5. Wascher TC. Oxidative stress and vascular complications in type 2 diabetes [Internet] 2006. [cited 2006 Aug 3]. Available from: http://www.servier.com/pro/ diabetologie/ diabetographia/ud/03.asp.

6. Schalkwijk CG, Stehouwer CDA. Vascular complications in diabetes mellitus: the role of endothelial dysfunction. Clinical Science. 2005;109:143-59.

7. Jacobsen DW. Homocysteine - To test and to treat [Internet] 2001. [cited $2006 \mathrm{Aug}$ 3]. Available from: http://www.dpcweb.com/medical/heartdisease/tech reports/ZB203-a.pdf.

8. Faldetta MC, Laurenti O, Desideri G, Bravi MC, De Luca O, Marinucci MC, De Mattia G, Ferri C. L-arginine infusion decreases plasma total homocysteine concentrations through increased nitric oxide production and decreased oxidative status in Type II diabetic patients. Diabetologia. 2002;45:1120-27.

9. Guldener CV, Stehouwer CDA. Diabetes Mellitus and hyperhomocysteinemia. Seminars in Vascular Medicine. 2002;2(1):351-59.

10. Cumurcu T, Sahin S, Aydin E. Serum homocysteine, vitamin $\mathrm{B}_{12}$ and folic acid levels in different types of glaucoma. BMC Ophthalmol [Internet] 2006. [cited 2007 March 29];6(6). Available from: http:// www.biomedcentral.com/1471-2415/6/6.

11. Spoelstra-de Man AME, Teerlink T, Brouwer CB, Rauwerda JA, Stehouwer CDA. No effect of B vitamins on ADMA levels in patients at increased cardiovascular risk. Clinical Endocrinology. 2006;64(5):495.

12. Meigs JB, Jacques PF, Selhub J, Singer DE, Nathan DM, Rifai N, D'Agostino RB, Wilson PWF. Fasting plasma homocysteine levels in the insulin resistance syndrome: The Framingham Offspring Study. Diabetes Care. 2001;24:1403-10

13. Tarkun I, Arslan BC, Cantürk Z, Tarkun P, Kozdağ G, Topsever P. Homocysteine concentrations in type 2 diabetes mellitus patients without cardiovascular disease: relationship to metabolic parameters and diabetic complications. Turkish Journal of Endocrinology and Metabolism. 2003;7(1):11-17. 
14. Abu-Lebdeh HS, Barazzoni R, Meek SE, Bigelow ML, Persson XT, Nair S. Effects of insulin deprivation and treatment on homocysteine metabolism in people with type 1 diabetes. The Journal of Clinical Endocrinology \& Metabolism. 2006;91(9):3344-48.

15. McCarty MF. Insulin secretion as a potential determinant of homocysteine levels. Med Hypotheses. 2000;55(5):454-55.

16. Fonseca V, Guba SC, Fink LM. Hyperhomocysteinemia and the endocrine system: implications for atherosclerosis and thrombosis. Endocrine Reviews. 1999;20(5):738.

17. Abott Diagnostics. Homocysteine estimation: Fluorescence polarization immuno assay (FPIA) AxSYM. Abbott Laboratories. Abbott Park, Illinois, U.S.A. 2006.

18. Stellingwerf C, Hardus PLLJ, Hooymans JMM. Two-field photography can identify patients with vision-threatening diabetic retinopathy a screening approach in the primary care setting. Diabetes Care. 2001;24:2086-90.

19. Forrester JV, Burden F, Hamilton AHM, Lavin M, Harding SP, Wong SHD, Talbot JF, Vora J, Williams R, Packer H. Guidelines for diabetic retinopathy [Internet] 2005. [cited 2006 Aug 3]. Available from: h t t p : / / w w w . r c o p h t h a c . u k / docs/scientific/DiabeticRetinopathyGuidelines2005.pdf.

20. Parvanova A, Iliev I, Dimitrov BD, Arnoldi F, Zaletel J, Remuzzi G, Ruggenenti P. Hyperhomocysteinemia and increased risk of retinopathy a cross-sectional, case-control study in patients with type 2 diabetes. Diabetes Care. 2002;25:2361.
21. Yang G, Lu J, Pan C. The impact of plasma homocysteine level on development of retinopathy in type 2 diabetes mellitus. Zhonghua Nei Ke Za Zhi (in Chinese). 2002;41(1):34-38.

22. Goldstein M, Leibovitch I, Yeffimov I, Gavendo S, Sela BA, Loewenstein A. Hyperhomocysteinemia in patients with diabetes mellitus with and without diabetic retinopathy. Eye. 2004;18(5):460-65.

23. Huang EJ, Kuo WW, Chen YJ, Chen TH, Chang MH, Lu MC, Tzang BS, Hsu HH, Huang CY, Lee SD. Homocysteine and other biochemical parameters in Type 2 diabetes mellitus with different diabetic duration or diabetic retinopathy. Clini Chim Acta 2006;366(1):293-98

24. Brazionis L, Rowley K, Itsiopoulos C, Harper CA, O'Dea K. Homocysteine and diabetic retinopathy. Diabetes Care. 2007;31(1):50-56.

25. Agulló-Ortuño MT, Albaladejo MD, Parra $\mathrm{S}$, Rodríguez-Manotas M, Fenollar M, Ruíz-Espejo F, Tebar J, Martínez P. Plasmatic homocysteine concentration and its relationship with complications associated to diabetes mellitus. Cliin Chim Acta 2002;326(1):105-12.

26. Hoogeveen EK, Kostense PJ, Eysink PE, Polak BC, Beks PJ, Jakobs C, Dekker JM, Nijpels G, Heine RJ, Bouter LM, Stehouwer CDA. Hyperhomocysteinemia is associated with the presence of retinopathy in type 2 diabetes mellitus: the Hoorn Study. Arch Intern Med. 2000;160(19):2984-90.

27. Becker A, Smulders YM,Guldener CV, Stehouwer CDA. Epidemiology of homocysteine as a risk factor in diabetes. Metabolic Syndrome and Related Disorders. 2003;1(2):105-20. 